CASE REPORT

\title{
Dual bronchial carcinoids and Cushing's syndrome with a paradoxical response to dexamethasone and a false positive outcome of inferior petrosal sinus sampling
}

\author{
Pia Burman ${ }^{1}$, ÅsaLinda Lethagen ${ }^{1}$, Krasnodar Ivancev ${ }^{2}$, Leif Johansson ${ }^{3}$ and Anders Sundin ${ }^{4}$ \\ Departments of ${ }^{1}$ Endocrinology, ${ }^{2}$ Radiology and ${ }^{3}$ Pathology, University Hospital MAS, SE-205 02 Malmö, Sweden and ${ }^{4}$ Department of Diagnostic \\ Radiology, University Hospital, Uppsala, Sweden
}

(Correspondence should be addressed to P Burman; Email: pia.a.burman@skane.se)

\begin{abstract}
Context: Establishing the cause of Cushing's syndrome (CS) can be a considerable challenge, in particular in ectopic adrenocorticotropic hormone (ACTH) syndrome, and often requires a combination of biochemical tests and imaging procedures.

Subject: A 27-year-old man presented with signs of CS. P-ACTH levels were three times above the upper limit of normal (ULN) and free urinary cortisol around $2000 \mathrm{nmol} / 24 \mathrm{~h}$. The work-up showed remarkable results.

Results: A 2-day low-dose dexamethasone suppression test demonstrated paradoxical increases in cortisol. Sampling from the bilateral inferior petrosal sinus sampling (BIPSS) showed a central to peripheral ACTH ratio of 4.7 after corticotrophin-releasing hormone (CRH) stimulation, i.e. indicated pituitary disease, but magnetic resonance imaging of the pituitary was normal. Computed tomography (CT) scan of the lungs showed two oval-shaped masses, $1.3 \times 1.8$ and $1.3 \times 2 \mathrm{~cm}$, in the middle lobe. Both were positive at somatostatin receptor scintigraphy, compatible with tumors or inflammatory lesions. Subsequently, ${ }^{11} \mathrm{C}$-5-hydroxytryptophan-PET showed distinct uptake in the tumors but not elsewhere. Two carcinoids situated $3 \mathrm{~cm}$ apart, both staining for ACTH, were removed at surgery. Conclusion: This unique case with dual bronchial carcinoids inducing hypercortisolism illustrates the problems with identifying the source of ACTH in CS. Possibly, an abnormal regulation of ACTH production in response to dexamethasone, or steroid-induced tumor necrosis, explains the paradoxical outcome at dexamethasone suppression, and the false positive result at BIPSS reflects an unusual sensitivity of the pituitary corticotrophs to $\mathrm{CRH}$ in this patient. The work-up illustrates the great value of ${ }^{11} \mathrm{C}$-5-hydroxytryptophan-PET as a diagnostic procedure when other investigations have produced ambiguous results.
\end{abstract}

European Journal of Endocrinology 159 483-488

\section{Introduction}

Differentiating between pituitary or ectopic adrenocorticotropic hormone (ACTH) production in Cushing's syndrome (CS) frequently presents a challenge, as in the individual case, no single or combination of dynamic tests accurately predicts a pituitary or non-pituitary source of ACTH $(1,2)$. Ectopic ACTH production accounts for $10-20 \%$ of all cases of CS and is most commonly associated with small cell carcinoma of the lung and intra-thoracic carcinoid tumors (2). The clinical features and the findings at laboratory work-up in CS due to carcinoid tumors may be indistinguishable from those in Cushing's disease (CD) (3-5).

The procedure of bilateral inferior petrosal sinus sampling (BIPSS) described in $1991(6,7)$ represented a breakthrough in the diagnosis of CS and remains the gold standard in the search for the source of ACTH. The sensitivity and the specificity of this procedure supersede all non-invasive dynamic tests, and for a long time a central to peripheral ACTH gradient of more than two in the basal state and/or more than three after corticotrophin-releasing hormone $(\mathrm{CRH})$ stimulation was considered to predict a pituitary ACTH source with close to $100 \%$ accuracy. Since then it has become apparent that the procedure is associated with an average of $5 \%$ false-negative tests, i.e. the absence of a central to peripheral ACTH gradient indicating an ectopic source, mostly due to problems with catheter positioning or aberrant venous drainage. There are also a few reports on false positive outcomes. These cases have been attributed to eucortisolism at the time of sinus sampling, an ectopic secretion of $\mathrm{CRH}$, or non-pituitary but centrally located ACTH production (4, 8-11).

Here we report an exceptional case of ACTHdependent CS in whom the work-up for the origin of ACTH produced unusual and ambiguous findings. 


\section{Case history}

A 27-year-old man with a history of lumbar pain for 3 years was found to have pronounced osteoporosis ( $T$-score of -3.3 in the lumbar region and -2.8 in the left hip at dual x-ray absorptiometry (DEXA)) and lumbar fractures at imaging. He was a previously healthy nonsmoking lacto-vegetarian with no family history of endocrine disease. Over the last 2-3 years he had gained $15 \mathrm{~kg}$ in weight, lost his libido, and since 1 year experienced weakness of the lower limbs. He had recently been started on an ACE-inhibitor (ramipril $5 \mathrm{mg}$ daily) due to hypertension and received calcium-vitamin D supplementation. At referral to the Department of Endocrinology he presented several signs of CS, such as facial plethora, truncal obesity, thinning of the proximal limb muscles, and purple striae on the abdomen, on the inner sides of the thighs, and in the axillary regions. The skin and hair growth were normal. He weighed $75 \mathrm{~kg}$ and was $172 \mathrm{~cm}$ tall. The blood pressure was 150/100 mmHg.

\section{Results}

\section{Lab}

At the first examination: B-Hemoglobin 168 (ref. 134-170) g/l, p-creatinine 51 (60-100) $\mu \mathrm{mol} / \mathrm{l}$, p-potassium $3.6(3.5-4.4) \mu \mathrm{mol} / \mathrm{l}$, fasting p-glucose 5.1 (4.2-6.3) mmol/l, urinary free cortisol (UFC) 2049 and 1801 ('183) nmol/24 h, p-ACTH 146 and 158 ( <46 ng/l, Immulite 2000, DPC, Los Angeles, CA, USA), s-testosterone 5.5-5.8 (10-35) nmol/l, s-testosterone/sex hormone binding globulin (SHBG) ratio $0.35(0.3-1.3)$, p-luteinizing hormone 1.3 (1.0-10) IE/l, p-follicle-stimulating hormone 7.5 (1.0-10) IE/l, s-insulin-like growth factor-I 83 (117-329) $\mu \mathrm{g} / \mathrm{l}, \quad S$-growth hormone $0.85 \mathrm{mIE} / \mathrm{l}$, p-prolactin $10 \quad(3-13) \mu \mathrm{g} / \mathrm{l}$, thyroid-stimulating hormone $0.9(0.4-3.5) \mathrm{mU} / \mathrm{l}_{4} \mathrm{fT}_{4} 9$ (8-14) pmol/l, $\mathrm{fT}_{3} 4.1$ (3.8-6.0) pmol/l, p-chromogranin $\mathrm{A}<10$ (0-18) IE/l, s-gastrin $20(<50) \mathrm{pmol} / \mathrm{l}, \mathrm{u}-5$-hydroxyindole acetic acid $27(<50) \mu \mathrm{mol} / 24 \mathrm{~h}$.

The circadian s-cortisol was abnormal: $0800 \mathrm{~h}, 482$; $1200 \mathrm{~h}, 542 ; 1600 \mathrm{~h}, 686 ; 2000 \mathrm{~h}, 707$; and at $2400 \mathrm{~h}, 751 \mathrm{nmol} / \mathrm{l}$. A two-day low-dose dexamethasone suppression test showed a paradoxical response of serum and urine cortisol (Table 1). Subsequently,

Table 1 Paradoxical increased cortisol response to a 2-day, lowdose dexamethasone suppression test $(0.5 \mathrm{mg} \times 4 \times \mathrm{II})$.

\begin{tabular}{lccr}
\hline & Basal & + day $\mathbf{1}$ & + day 3 \\
\hline S-Cortisol nmol/l & 482 & 921 & 1423 \\
UFC & 534 & 5147 & $>3000^{\mathrm{a}}$ \\
\hline
\end{tabular}

a Sample was not further diluted. blood sampling from the inferior petrosal sinuses before and after an i.v. dose of $100 \mu \mathrm{g}$ synthetic human $\mathrm{CRH}$ (Ferring $\mathrm{GmbH}$ ) showed an increase in p-ACTH both at 2 and 5 min after injection. The calculated stimulated central to peripheral ACTH ratio was $4.7,>3$ indicating a pituitary origin. At baseline the gradient was $<2$ (1.2) (Table 2). There was no venous anomaly at angiography. Plasma $\mathrm{CRH}$ sampled from the right atrium during BIPSS was $<1 \mathrm{pmol} / \mathrm{l}$ (reference level $<5$ ), as determined by an RIA after extraction of small peptides in use at the Department of Clinical Chemistry, Karolinska Hospital, Stockholm, Sweden.

\section{Imaging}

Magnetic resonance imaging (MRI) of the pituitary was normal. Chest X-ray showed a rounded opacity in the lower part of the right lung, $\sim 1 \mathrm{~cm}$ in size. Computed tomography (CT) examination of the thorax revealed two oval-shaped masses, $1.3 \times 1.8$ and $1.3 \times 2 \mathrm{~cm}$ respectively in the middle lobe of the lung (Fig. 1, upper part). Somatostatin receptor scintigraphy showed two rounded lesions with moderate uptake in the right thorax corresponding to the lesions seen on CT. ${ }^{11} \mathrm{C}$-5-hydroxy-tryptophan-PET (12) showed high focal tracer uptake corresponding to the two lesions depicted by CT but not elsewhere in the body (Fig. 1, lower part).

\section{Clinical course}

After referral the patient was started on bisphosphonates and continued calcium-vitamin D supplementation. Treatment with ketoconazole at a low dose (200 mg bid) was given once the laboratory investigations were completed, and halted 6 days later when an opportunity rose to perform BIPSS. No ketoconazole was given during the 2 weeks preceding the BIPSS. On the day of the procedure, the ACTH and cortisol levels were in the same range as repeatedly found at investigations prior to ketoconazol.

Ketoconazole was restarted after BIPSS, and after 3 weeks a dose of $800 \mathrm{mg}$ controlled the hypercortisolism. The patient underwent surgery and the middle lobe was resected. Two tumors $3 \mathrm{~cm}$ apart were found, measuring 1.2 and $1.4 \mathrm{~cm}$ in diameter respectively. There was about $2 \mathrm{~cm}$ resection margin and no lesions in the regional lymph nodes. After surgery, ACTH levels were below the lower limit of detection and the patient received standardized hydrocortisone replacement. Twelve months post surgery, the patient was well with remission of cushingoid features, normal testosterone levels and libido, and a normal blood pressure. Bone mineral density was improved; the $\mathrm{T}$ score had increased from -3.3 to -2.0 in the lumbar region and from -2.8 to -2.3 in the hip. The cortisol response at an ACTH stimulation test was still subnormal and a low dose of hydrocortisone (10 mg) replacement therapy was given. 
Table 2 Bilateral inferior petrosal sinus sampling.

\begin{tabular}{lccccc}
\hline & \multicolumn{5}{c}{ P-ACTH (pmol/l) } \\
\cline { 2 - 6 } Level & -2 min & 0 min & CRH +2 min & CRH +5 min & Central/peripheral quotient $^{\mathrm{a}}$ \\
\hline V. cava inf & 34 & - & - & - & \\
Right atrium & 35 & - & - & 38 & 1.1 \\
Peripheral vein & 36 & 36 & 36 & 41 & 4.7 \\
Right spi $^{\mathrm{b}}$ & 37 & 41 & 100 & 180 & \\
Left spi $^{\mathrm{b}}$ & 41 & & & & \\
\hline
\end{tabular}

S-Cortisol $624 \mathrm{nmol} / \mathrm{l}$ and $\mathrm{CRH}<1.0$ (ref. $<5$ ) pmol/l at time of investigation.

${ }^{a}$ Quotient $\geq 3$ after $\mathrm{CRH}$ stimulation is considered to predict a pituitary production of $\mathrm{ACTH}$.

${ }^{\mathrm{b}} \mathrm{spi}=$ inferior petrosal sinus. P-ACTH ref. range 2.0-10.0 pmol//, Immulite, DPC, Los Angeles, CA, USA.

\section{Histological and immunohistochemical examinations}

Both tumors had the same histological appearance, growing in strands and nests. The atypia was mild and mitoses rare. Proliferation index measured by the Mib-1 antibody (Ki-67) was very low, below 1\%. Immunohistochemical staining for synaptophysin (Fig. 2, left) and ACTH (Fig. 2, right) showed diffuse and strong positivity in all tumor cells. Both tumors were classified as typical carcinoids. There were no tumorlets or endocrine cell hyperplasia in the resected tissue.

\section{Discussion}

The clinical presentation of prodigious hypercortisolism with marked elevations of ACTH levels in a man with a pulmonary nodule at chest X-ray is highly suggestive of an ectopic ACTH syndrome. The present case, however, presented ambiguous results at further work-up; a paradoxical increase in cortisol in response to dexamethasone, a BIPSS pointing to a pituitary origin of ACTH, a normal MRI of the pituitary gland, and two oval-shaped lesions in the middle lobe of the lung at a CT scan. Both were positive at somatostatin receptor
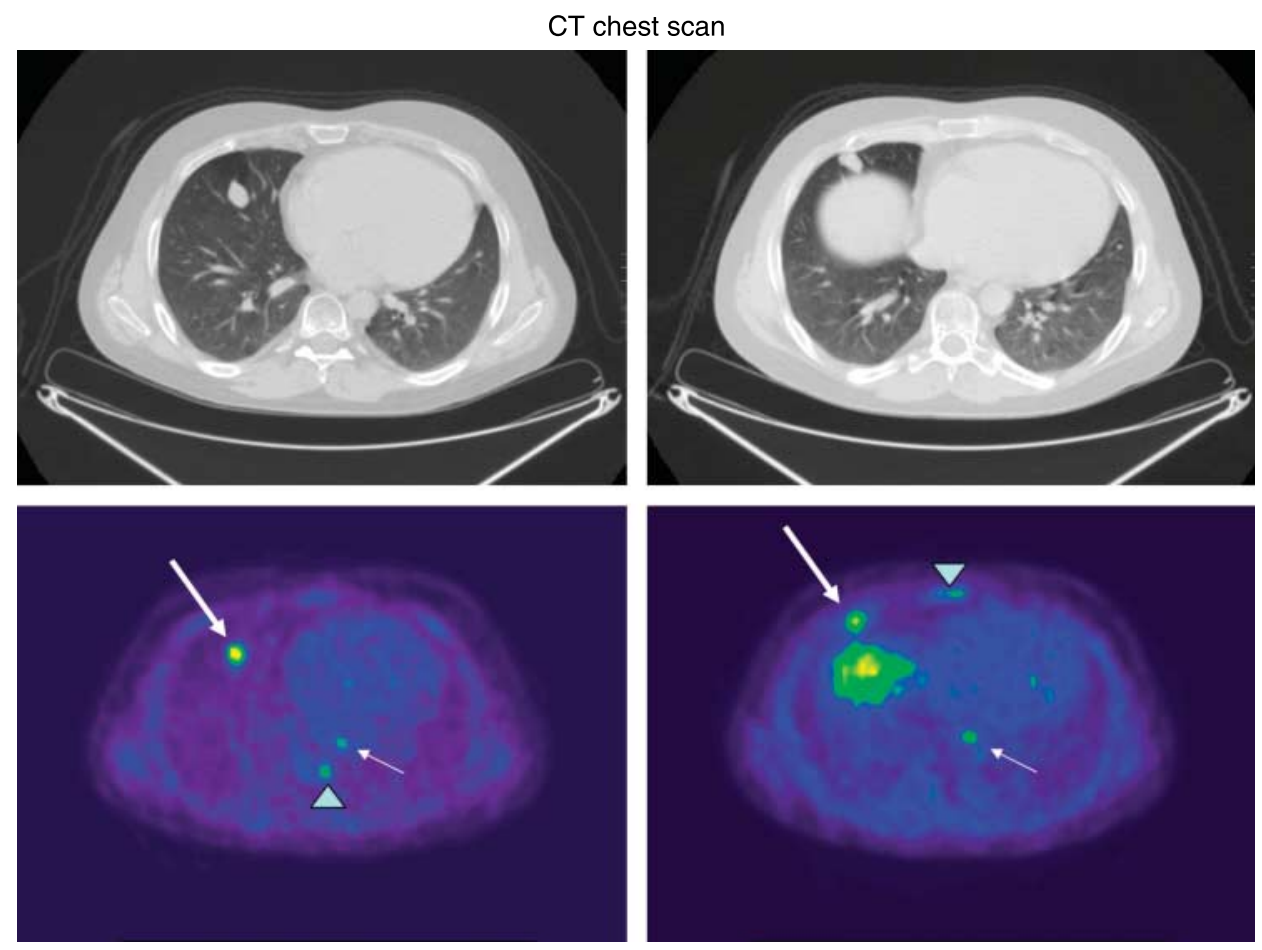

${ }^{11} \mathrm{C}-5$-hydroxytryptophan PET scan

Figure 1 Transaxial CT chest (upper) and corresponding ${ }^{11} \mathrm{C}-5$-HPT-PET images (lower) displaying two pathological lesions (thick arrows) in the middle lobe of the lung measuring $1.3 \times 2 \mathrm{~cm}$ (more centrally located) and $1.3 \times 1.8 \mathrm{~cm}$ (more peripherally located). Physiological tracer accumulation is generally seen in the esophagus (thin arrows) and in bone (arrowheads) represented by a vertebral body (left) and the sternum (right). 

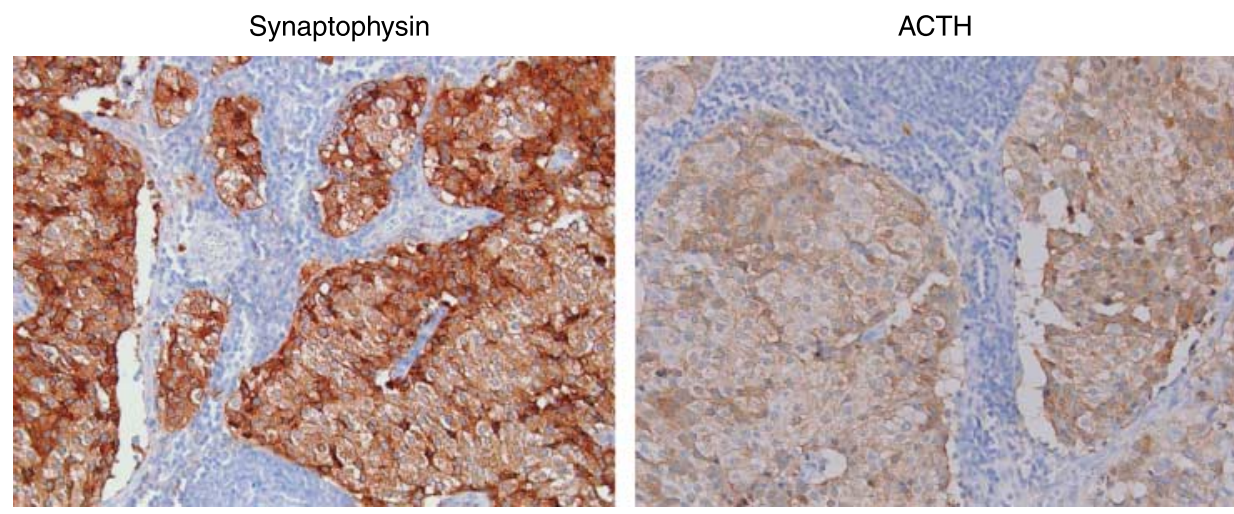

Figure 2 Staining of the tumor cells with antibodies to synaptophysin (left) and ACTH (right). Original magnification $\times 100$.

scintigraphy, a finding that is compatible with, but not diagnostic for tumors, since inflammatory processes may express somatostatin receptors (13).

At this point we faced different and unusual scenarios, either a central origin of ACTH overproduction and two unrelated lesions in the lung, or ectopic ACTH production from two primary pulmonary tumors, or theoretically ectopic ACTH production of a pituitary metastasis from a neuroendocrine tumor, although it seems probable that a pituitary metastasis would have been visible on MRI. Neuroendocrine tumors have a capacity for uptake and decarboxylation of amine precursors like 5-hydroxytryptophan (5-HPT), which can be used as a tracer for PET imaging (12). Compared with $\mathrm{CT}$ and somatostatin receptor scintigraphy ${ }^{11} \mathrm{C}-5-$ HTP-PET has been shown to visualize more and smaller lesions $(12,14)$. Also, because of the biochemical pathway of 5-HPT, the nature of a lesion may be demonstrated (12, 14) and, contrary to somatostatin receptor scintigraphy, inflammatory lesions do generally not accumulate the tracer. In our case, the 5-HPT-PET showed a high tracer uptake in the two tumors in the middle lobe of the lung and no uptake elsewhere. The patient was referred to surgery and the tumors could be removed.

The incidence of CS in subjects with bronchial carcinoids is around 1\% (15). Bronchial tumorlets are multiple small nests ( $\leq 5 \mathrm{~mm}$ in greatest dimension) of endocrine cell hyperplasia, disseminated in the lung parenchyma or in close proximity to a carcinoid tumor (16-18). The tumorlets are often seen in association with chronic inflammatory conditions such as bronchiectasis (19). It has been hypothesized that the small nests represent precursor lesions to pulmonary carcinoids, or intramucosal metastatic dissemination from a tumor. However, in subjects who had both a carcinoid tumor and tumorlets the two types of lesions had discordant genotypes arguing against the latter hypothesis (20). Occasional case reports on CS due to tumorlets have been published (21-24), whereas CS caused by more than one carcinoid tumor (i.e tumor dimension $>5 \mathrm{~mm}$ ) is very rare without a concomitant presence of multiple tumorlets. To our knowledge, there is only one such previous case report (25). This patient had three bronchial adenomas of which at least one was a carcinoid. In a large series of 294 patients with pulmonary tumorlets and/or carcinoid tumors evaluated at the Mayo Clinic Rochester, 28 patients were found to have multiple lesions, either at imaging or at pathological examination post surgery. Out of these, the majority had multiple tumorlets. Five patients, all middle-aged or elderly women, had two carcinoid tumors. Two out of the 28 patients with multiple lesions had CS and it was not specified whether these patients had multiple tumorlets or two carcinoid tumors (18).

A paradoxical increase in serum and urine cortisol levels on a low-dose dexamethasone suppression test, as seen in the present case, has previously been reported in CD, in patients with ectopic ACTH production (26-29), and in primary pigmented nodular adrenocortical dysplasia (30). Several of these responses have occurred in patients with cyclic CS and were thought to be merely coincidental with periods of increased endogenous tumor activity $(25,26)$. Consistent paradoxical responses upon repeat tests as reported in a case with CD (31) argue, however, against such findings as being serendipitous. There are examples of abnormal responses to exogenous steroids in patients with ACTH-dependent CS. No suppression of ACTH in response to dexamethasone, although intact response to i.v. hydrocortisone, have been described in two case reports $(32,33)$. An apparent feed-forward regulation by glucocorticoids of ACTH release was reported in a case with ectopic ACTH production due to a pheochromocytoma. In this case dexamethasone was in vitro found to induce the production of ACTH precursors (34). We speculate that an alternative explanation for a paradoxical increase in cortisol could be apoptosis in ACTH producing cells induced by dexamethasone. Glucocorticoid-induced apoptosis is a well established phenomenon in a variety of cell lines (35) and forms the basis for using steroids in the treatment of certain malignancies.

In the present case, the BIPSS wrongly indicated a pituitary source of ACTH. Few reports on a false positive 
outcome in ectopic CS have been published. Some tumors co-secrete $\mathrm{CRH}$ which thereby could counteract a suppression of normal pituitary corticotrophs during hypercortisolism (36-40). In these reports, CRH levels in peripheral blood were found to be clearly elevated in two of the patients $(38,40)$ and within the normal range in one case (38). In our patient, $\mathrm{CRH}$ was below the detection limit in plasma at the time of BIPSS. An alternative explanation for a false finding at BIPSS could be that the investigation was not performed during hypercortisolism $(11,41)$. However, in the present case there was no history of periods with amelioration of symptoms during the 3 years preceding the diagnosis. Furthermore, during the period of work-up there was no occasion with UFC less than two times the ULN and plasma ACTH remained about three times above the ULN during repeat sampling. The patient had been treated with a low dose of ketoconazole for less than a week and no medication was given during the 2 weeks preceding the BIPSS. At the day of the procedure, cortisol and ACTH levels were the same as during the initial work-up. Therefore, one might suggest that stimulation with a high, unphysiologic dose of $\mathrm{CRH}$, like the one used in CRH tests, may awaken dormant pituitary corticotrophs in a patient with particular sensitivity. The fact that there was no central/peripheral gradient in the basal state in spite of the markedly elevated ACTH levels argues, however, per se for an ectopic source of ACTH and underlines that a calculated ratio must be interpreted against the full clinical picture.

In conclusion, the present case illustrates diagnostic dilemmas sometimes encountered in the work-up of CS. The paradoxical increase in cortisol in response to dexamethasone may reflect properties of this unusual tumor, whereas the outcome at BIPSS is unlikely to be related to the bronchial carcinoids. The data caution for relying on a positive gradient at BIPSS as the sole support for a central origin of ACTH, and demonstrates the value of ${ }^{11} \mathrm{C}$-5-HPT-PET before surgical intervention in cases where other investigations have produced ambiguous results.

\section{Declaration of interest}

The authors declare that there is no conflict of interest that would prejudice the impartiality of this scientific work.

\section{References}

1 Newell-Price J, Trainer P, Besser M \& Grossman A. The diagnosis and differential diagnosis of Cushing's syndrome and PseudoCushing's states. Endocrine Reviews 199819 647-672.

2 Newell-Price J, Bertagna X, Grossman AB \& Nieman LK. Cushing's syndrome. Lancet 2006367 1605-1617.

3 Ilias I, Torpy DJ, Pacak K, Mullen N, Wesley RA \& Nieman LK. Cushing's syndrome due to ectopic corticotrophin secretion: twenty years' experience at the National Institutes of Health. Journal of Clinical Endocrinology and Metabolism $2006 \mathbf{9 0}$ 4955-4962.
4 Isidori AM, Kaltsas GA, Pozza C, Frajese V, Newell-Price J, Reznek RH, Jenkins PJ, Monson JP, Grossman AB \& Besser GM. The ectopic adrenocorticotropin syndrome: clinical features, diagnosis, management, and long-term follow-up. Journal of Clinical Endocrinology and Metabolism 199991 371-377.

5 Findling JW \& Raff JW. Clinical review: Cushing's syndrome: important issues in diagnosis and management. Journal of Clinical Endocrinology and Metabolism 200691 3746-3753.

6 Oldfield EH, Doppman JL, Nieman LK, Chrousos GP, Miller DI, Katz DA, Cutler GB \& Loriaux DL. Petrosal sinus sampling with and without corticotrophin-releasing hormone for the differential diagnosis of Cushing's syndrome. New England Journal of Medicine 1991P 325 897-905.

7 Findling JW, Kehoe ME, Shaker JL \& Raff H. Routine inferior petrosal sinus sampling in the differential diagnosis of ACTHdependent Cushing's syndrome: early recognition of the occult ectopic ACTH syndrome. Journal of Clinical Endocrinology and Metabolism 199173 408-413.

8 Lindsay IR \& Nieman LK. Differential diagnosis and imaging in Cushing's syndrome. Endocrinology and Metabolism Clinics of North America 200534 403-421.

9 Invitti C, Giraldi FP, De Martin M, Cavagnini F \& and the Study Group of the Italian Society of Endocrinology on the Pathophysiology of the Hypothalamic-Pituitary-Adrenal Axis. Diagnosis and management of Cushing's syndrome; results of an Italian multi-centre study. Journal of Clinical Endocrinology and Metabolism 199984 440-448.

10 Salgado LR, Villares Fragoso MCB, Knoepfelmacher M, Machado MC, Domenice S, Pereria MAA \& de Mendonca BB. Ectopic ACTH syndrome: our experience with 25 cases. European Journal of Endocrinology 2006155 725-733.

11 Swearingen B, Katznelson L, Miller K, Grinspoon S, Waltman A, Dorer DJ, Klibanski A \& Biller BMK. Diagnostic errors after inferior petrosal sinus sampling. Journal of Clinical Endocrinology and Metabolism 200480 3752-3763.

12 Orlefors H, Sundin A, Garske U, Juhlin C, Oberg K, Skogseid B, Langstrom M, Bergstrom $M$ \& Eriksson B. Whole-body 11C-5-hydroxytryptophan positron emission tomography as a universal imaging technique for neuroendocrine tumors. Comparison with somatostatin receptor scintigraphy and computed tomography. Journal of Clinical Endocrinology and Metabolism 2005 $903392-3400$.

13 Tabarin A, Valli N, Chanson P, Bachelot Y, Rohmer V, BexBachellerie V, Catargi B, Roger P \& Laurent F. Usefulness of somatostatin receptor scintigraphy in patients with occult ectopic adrenocorticotropin syndrome. Journal of Clinical Endocrinology and Metabolism 199984 1193-1202.

14 Koopmans KP, Neels OC, Kema IP, Elsinga PH, Sluiter WJ, Vanghillewe K, Brouwers AH, Jager PL \& de Vries EG. Improved staging of patients with carcinoid and islet cell tumors with ${ }^{18} \mathrm{~F}$-dihydroxyphenyl-alanine and ${ }^{11} \mathrm{C}-5$-hydroxy-tryptophan positron emission tomography. Journal of Clinical Oncology 200826 1489-9513.

15 Limper AH, Carpenter PC \& Scheithauer B. The Cushing syndrome induced by bronchial carcinoid tumours. Annals of Internal Medicine 1992117 209-214.

16 Miller MA, Mark GJ \& Kanarek D. Multiple peripheral pulmonary carcinoids and tumorlets of carcinoid type, with restrictive and obstructive lung disease. American Journal of Medicine 197865 373-378.

17 Akashiba T, Matsumoto K, Kosaka N, Saito O, Horie T \& Nemoto N. Multifocal peripheral bronchial carcinoid tumour. Respirology 19994 199-201.

18 Aubry M-C, Thomas CF, Jett JR, Swensen SJ \& Myers JL. Significance of multiple carcinoid tumors and tumorlets in surgical lung specimens. Chest 2007131 1635-1643.

19 Watanabe H, Kobayashi H, Honma K, Ohnishi Y \& Iwafuchi M. Diffuse panbronciolitis with multiple tumorlets: a quantative study of the Kulchitsky cells and the clusters. Acta Pathologica Japonica $1985351221-12231$. 
20 Finkelstein SD, Hasegawa T, Colby T \& Youselm SA. 11 q 13 allelic imbalance discriminates pulmonary carcinoids from tumorlets. A microdissection-based genotyping approach useful in clinical practice. American Journal of Pathology $1999155633-640$.

21 Arioglu E, Doppman J, Gomes M, Kleiner D, Mauro D, Barlow C \& Papanicolaou DA. Cushing's syndrome caused by corticotropin secretion of pulmonary tumorlets. New England Journal of Medicine $1998339883-886$.

22 Rodgers-Sullivan RF, Weiland LH, Palumbo PJ \& Hepper NG. Pulmonary tumorlets associated with Cushing's syndrome. American Review of Respiratory Disease 1978117 799-806.

23 Ozbey N, Bozbora A, Kalayci G, Kaparan Y, Yilmazbayhan D, Dizdaroglu F, Orhan Y, Sencer E \& Molvalilar S. Cushing's syndrome caused by ectopic corticotrophin secretion by multiple pulmonary carcinoids and tumorlets of carcinoid type. Journal of Endocrinological Investigation 200023 536-541.

24 Liu SM, Wu HH, Wu CJ, Kuo CL \& Mo LR. Adrenocorticotropinproducing pulmonary tumorlets with lymph node metastasis. Pathology International 200353 883-886.

25 Sobota JT \& Reed RJ. Multiple bronchial adenomas, Cushing's syndrome and hypokalemic alkalosis. Diseases of the Chest $1964 \mathbf{4 6}$ 367-371.

26 Brown RD, van Loon GR, Orth DN \& Liddle GW. Cushing's disease with periodic hormonogenesis: one explanation for paradoxical response to dexamethasone. Journal of Clinical Endocrinology and Metabolism 197336 445-451.

27 Lieberman B, Wajchenberg BL, Tambascia MA \& Mesquita CH. Periodic remission in Cushing's disease with paradoxical dexamethasone response: an expression of periodic hormonogenesis. Journal of Clinical Endocrinology and Metabolism 197643 913-918.

28 Chajek T \& Romanoff H. Cushing syndrome with cyclic edema and periodic secretion of corticosteroids. Archives of Internal Medicine $1976136441-443$.

29 De Feo ML, Bonfanti L, Romano S, Fusi S, Giusti G, Messeri G \& Forti G. Cyclical Cushing's disease: report of a case cured by conventional cobaltotherapy. Journal of Endocrinological Investigation 198710 89-93.

30 Koch CA, Bornstein SR, Chrousos GP \& Stratakis CA. Primary pigmented nodular adrenoortical dysplasia (PPNAD) within the scope of Carney complex as the etiology of Cushing syndrome. Medizinische Klinik 200095 224-230.

31 Atkinson AB, Kennedy AL, Carson DJ, Hadden DR, Weaver JA \& Sheridan B. Five cases with cyclical Cushing's syndrome. BMJ $19852911453-1457$.
32 Carey R. Suppression of ACTH by cortisol in dexamethasonenonsuppressible Cushing's disease. New England Journal of Medicine 1980302 275-279.

33 Mercado-Asis LB, Murayama M, Yamakita N, Morita H, Mune T, Yasuda K \& Miura K. Cortisol-suppressible dexamethasonenonsuppressible cyclic Cushing's disease with evidence of clinical and biochemical remission with bromocriptine. Endocrinologia Japonica 199138 315-324.

34 White A, Ray DW, Talbot A, Abraham A, Thody AJ \& Bevan JS. Cushing's syndrome due to a phaeochromocytoma secreting precursors of adrenocorticotropin. Journal of Clinical Endocrinology and Metabolism $2000 \mathbf{8 5} 4771-4775$.

35 Plasiey SL \& Litwack G. Glucocorticoid-induced apoptosis in lymphocytes. Biochemical and Biophysical Research Communications 2000279 307-312.

36 Carey ML, Varma SK, Drake CR, Thorner MO, Kovacs K, Rivier J \& Vale W. Ectopic secretion of corticotropin-releasing factor as a cause of Cushing's syndrome. New England Journal of Medicine $198531113-20$.

37 Belsky JL, Cuello B, Swanson LW, Simmons DM, Jarrett RM \& Braza F. Cushing's syndrome due to ectopic production of corticotropin-releasing factor. Journal of Clinical Endocrinology and Metabolism $1985 \mathbf{6 0} 496-500$.

38 Case 52-1987. Case records of the Massachusetts General Hospital. New England Journal of Medicine 1987317 1648-1658.

39 O'Brien T, Young WF, Davila DG, Scheithauer BW, Kovacs K, Horvath E, Vale W \& van Heerden JA. Cushing's syndrome associated with ectopic production of corticotrophin-releasing hormone, corticotrophin and vasopressin by a phaeochromocytoma. Clinical Endocrinology 199237 460-467.

40 Young J, Deneux C, Grino M, Oliver C, Chanson P \& Schaison G. Pitfall of petrosal sinus sampling in a Cushing's syndrome secondary to ectopic adrenocorticotropin-corticotropin releasing hormone (ACTH/CRH) secretion. Journal of Clinical Endocrinology and Metabolism $1998 \mathbf{8 3} 305-308$.

41 Yamamoto Y, Davis DH, Todd B, Nippoldt TB, Young WF, Huston J \& Parisi JE. False-positive petrosal sinus sampling in the diagnosis of Cushing's disease. Report of two cases. Journal of Neurosurgery 199583 1087-1091.

Received 3 July 2008

Accepted 10 July 2008 